\title{
A rare case of twisted hydrosalpinx with CONTUA: ESHERE: ESGE: Class IV a COV0 uterine anomaly
}

\author{
Manish Pandya ${ }^{1 *}$, Divya Tekani ${ }^{2}$, Shrina Shah ${ }^{3}$ \\ ${ }^{1} \mathrm{HOD},{ }^{2}$ Associate professor ${ }^{3}$ Resident, Dept. of Obstetrics and Gynecology, Scientific Research Institute, ${ }^{2} \mathrm{C}$ U Shah Medical Collage \\ Surendranagar, Gujarat, India
}

*Corresponding Author: Manish Pandya

Email: drmanish.pandya@gmail.com

Received: $25^{\text {th }}$ April, 2019

Accepted: $18^{\text {th }}$ May, 2019

\begin{abstract}
A hydrosalpinx is a condition that occurs when the fallopian tube is blocked and fills with serous or clear fluid near the ovary (distal to the uterus). The blocked tube may become substantially distended giving the tube a characteristic sausage-like or retort-like shape. The condition is often bilateral and the affected tubes may reach several centimeters in diameter. The blocked tubes cause infertility.

A fallopian tube filled with blood is a hematosalpinx, and with pus a pyosalpinx.
\end{abstract}

Keywords: Haemetosalpinx, Bicornuate uterus, Contua, Ehsre, Esge.

\section{Introduction}

A hydrosalpinx is a term given to describe heterogenous group of conditions with distal tubal occlusion collection of watery fluid in the tube. The blocked tube may become substantially distended giving the tube a characteristic sausage-like or retort-like shape. The condition is often bilateral and the affected tubes may reach several centimeters in diameter. ${ }^{1}$

In hydrosalpinx simplex, excessive distension and thinning of walls of tube and very few widely separated plicae are seen. In contrast to this hydrosalpinx follicularis, includes tube without any central cystic cavity, the lumen being broken into compartments as a result of fusion of tubal plicae. ${ }^{2}$
Etiology of hydrosalpinx includes PID, ectopic pregnancy $^{3}$ (haematosalpinx more common), previous abdominal surgery, Endometriosis and congenital malformation of uterus. ${ }^{1}$

Uterine malformation in general population is around $3 \%$ to $5 \%{ }^{4}$ Abnormal fusion of the para-mesonephric duct (mullerian duct) during embryonic life results in a variety of congenital uterine malformations. ${ }^{2}$

Bicornuate uterus is typically classified based on whether or not the division extends to the external cervical os. Bicornuate uteri with a division above the os are called bicornuate unicollis and those with a divided os are called bicornuate bicollis.

According to the new ESHRE classification this was a case of U4aV0C0 uterine malformation. ${ }^{5}$

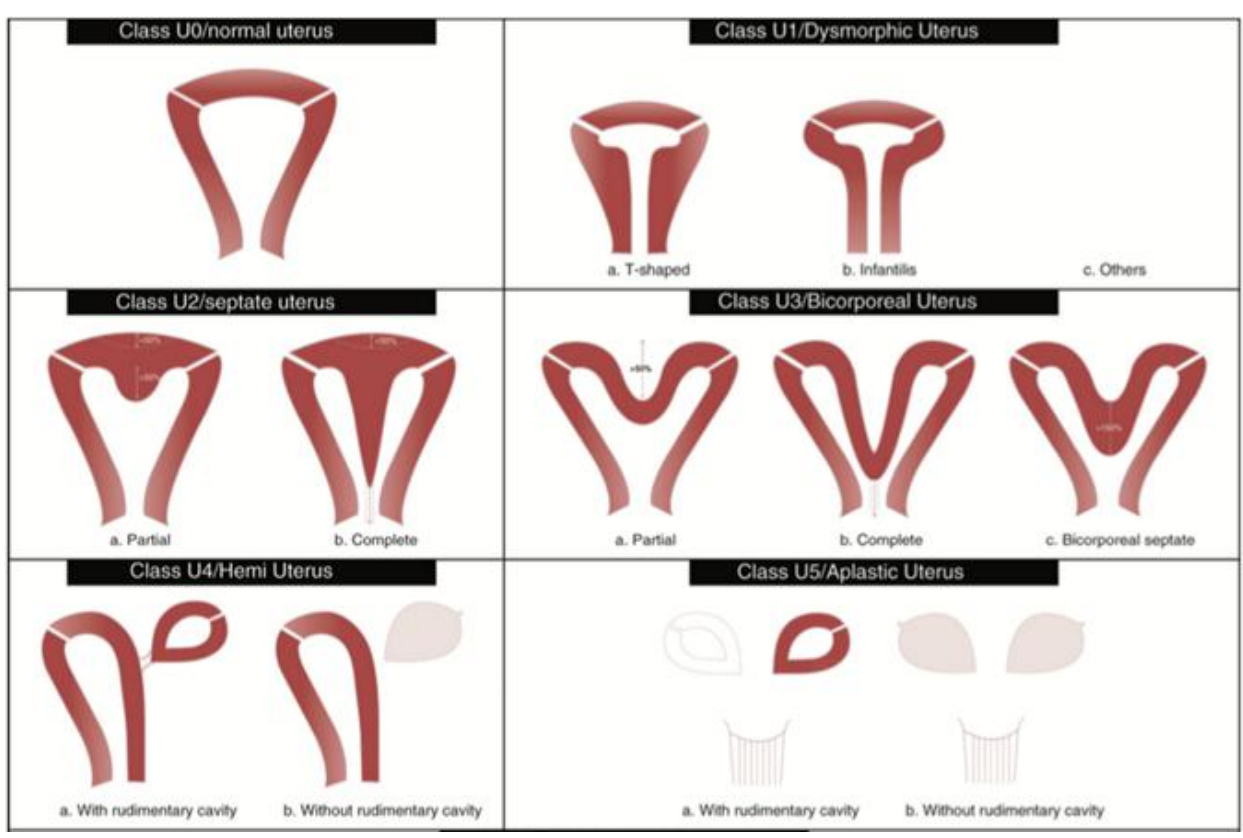

CONTUA: ESHRE/ESGE: classification of uterine anomalies 


\section{Case Report}

A 18 yrs old unmarried female came to opd with complaint of mild lower abdominal pain since 6-7 hours. Her last menstrual period date was $(27 / 04 / 2018)$.

On Examination: Blood pressure $-110 / 70 \mathrm{mmHg}$, Pulse rate $-90 / \mathrm{bpm}$, respiratory rate $-16 / \mathrm{min}, \mathrm{SPO}_{2}-98 \%$ \& per abdominally mild tenderness present over left iliac fossa.

USGfindings \& Doppler study: Uterus -anteverted $7 \mathrm{~cm} * 3 \mathrm{~cm} * 2.6 \mathrm{~cm}$,

Transabdominal Ultrasound: two horns, one horn measuring $6 * 7 \mathrm{~cm}$ (ground glass appearance) and other $2.6 * 2.25 \mathrm{~cm}$. Left sided anechoic mass of $9 * 8 \mathrm{~cm}$ hydosalpinx

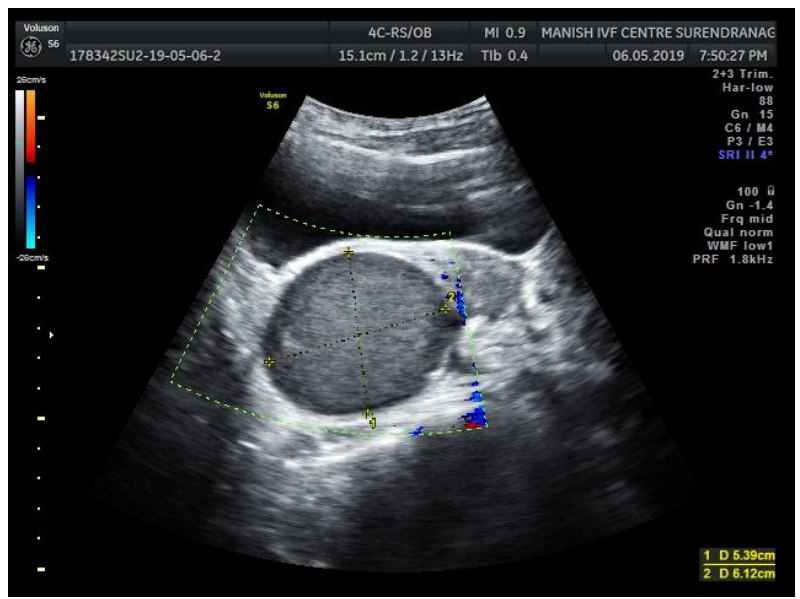

usg shows hemato metra in left cornu

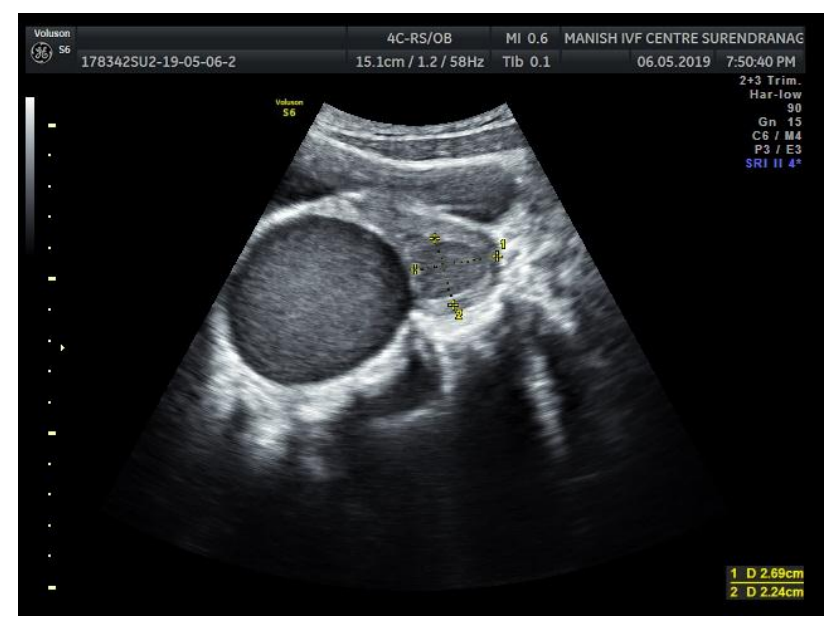

Right cornu measuring $2.6 \mathrm{~cm} * 2.24 \mathrm{~cm}$

Doppler: no flow seen

Ovaries; b/l normal

s/o left twisted hydrosalpinx with haematometra in non communicating horn.

Investigation: $\mathrm{Hb}-10 \mathrm{gm} \%$, WBC-10800cumm, Platelets379000cumm, BG Rh - o positive, HIV- NR, $\mathrm{HB}_{\mathrm{S}} \mathrm{AG}-$ NR,RBS-108mg/dl, Urea-24.2mg/dl, Creatinine- $0.69 \mathrm{mg} / \mathrm{dl}$.

$\mathrm{Ct}$ scan confirmed the findings of usg and showed hemi uterus with $5 * 6 \mathrm{~cm}$ haematometra in left non communicating horn. ${ }^{6}$
Left tube hydrosalpingx $9 * 8 \mathrm{~cm}$.

left ovary normal

Right tube and ovary normal

\section{Management}

A 18 years old unmarried female came to opd for mild pain in lower abdomen. As per USG finding she was diagnosed as twisted hydrosalpinx with haematometra in non communicating horn. USG report conveyed to patient. I/v Antibiotics were administered and consent was obtained for operative intervention.

During laparoscopy, $10 \mathrm{~mm}$ umbilical port was inserted followed by two $5 \mathrm{~mm}$ ports each side on the spinoumbilical line. Left fallopian tube with hydrosalpinx was noted to be twisted twice on itself. Left ovary was normal. The tube was untwisted to check for the vitality of the tissue. Because of the inability of the tissue to regain its pink colour, descision for its removal was taken, so Left salpingectomy was performed.

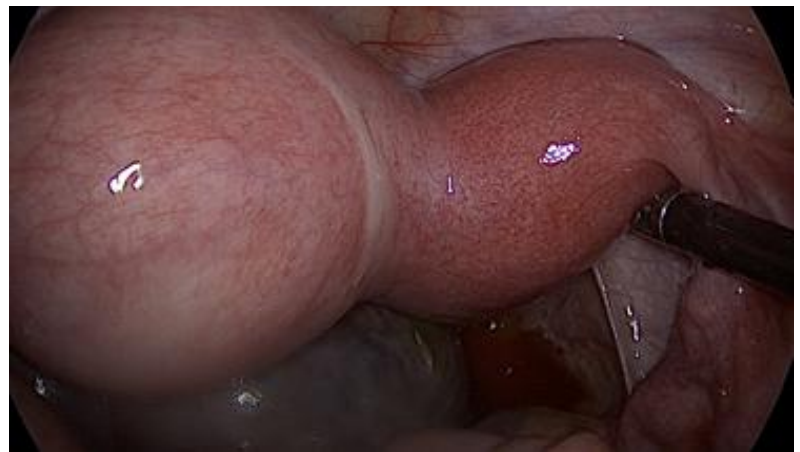

Fig. 1: Hemi uterus

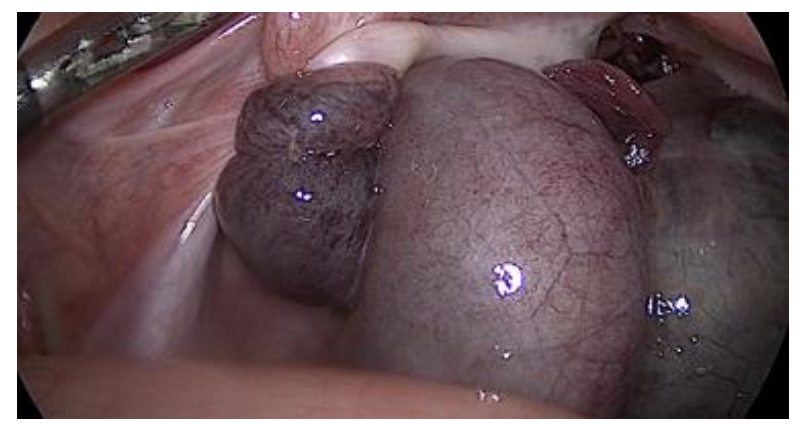

Fig. 2: left twisted hydrosalpinx

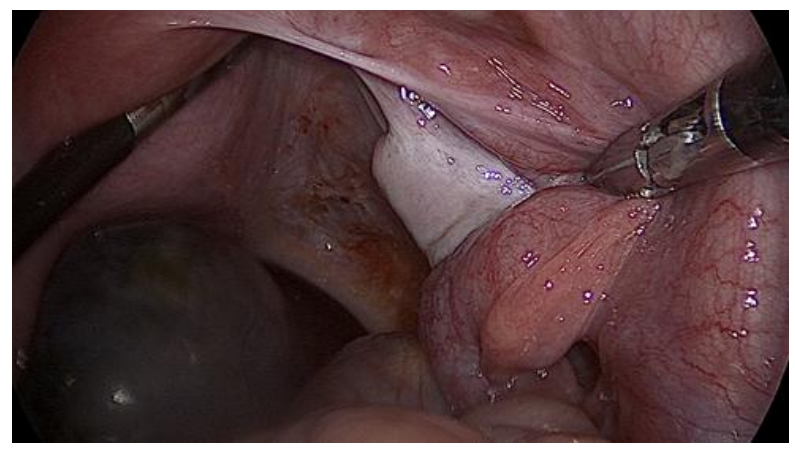

Fig. 3: Right side normal tube and ovary 


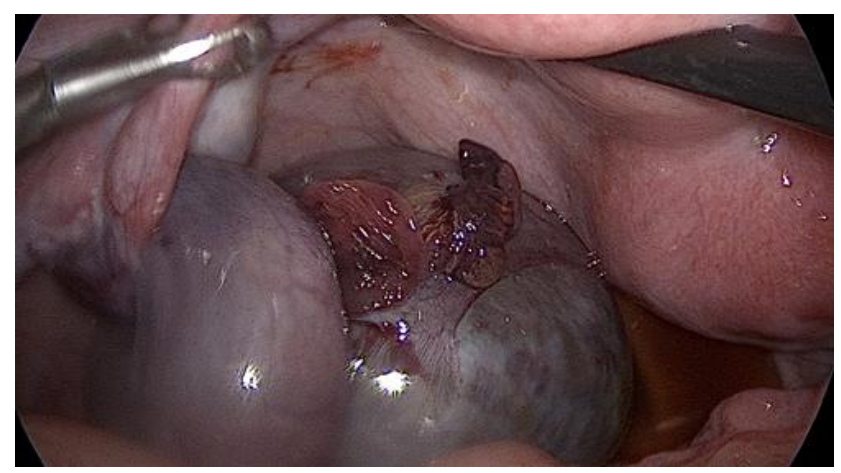

Fig. 4: Unwtisting (detorsion) of hydrosalpinx done (non viable tissue)

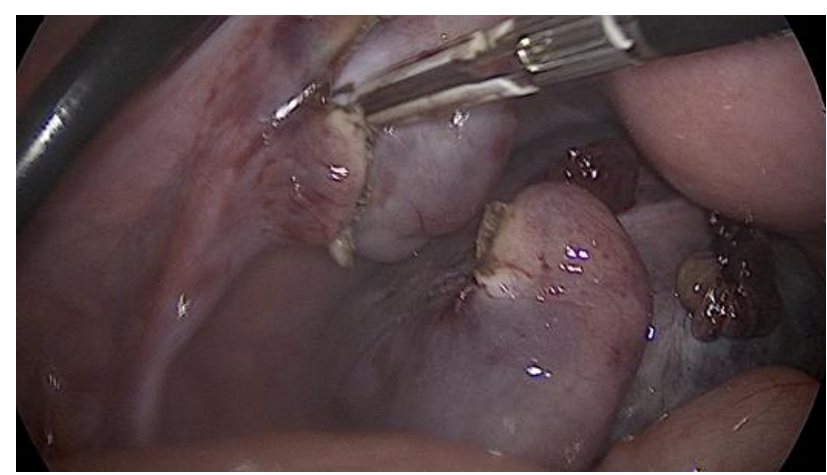

Fig. 5: Left salpingectomy done with vessel seller

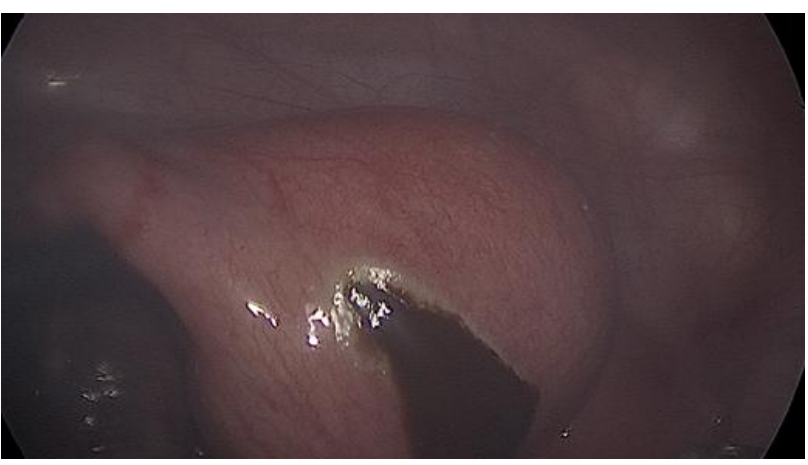

Fig. 6: Hematometra drained form left non communicating cornu

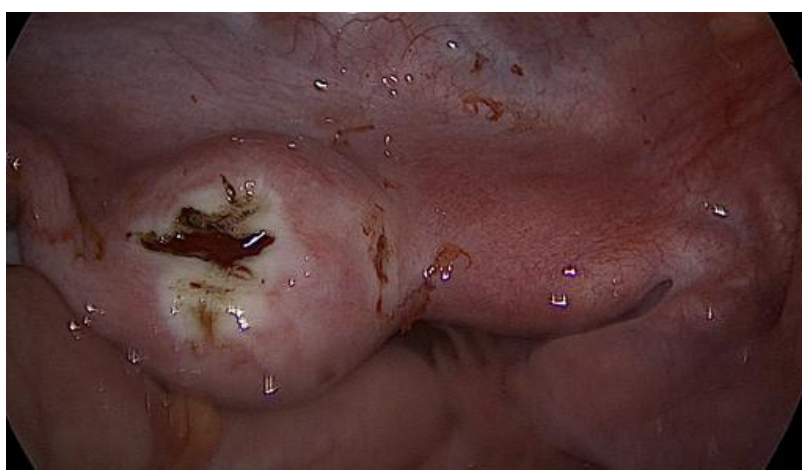

Fig. 7: CLASS iva COV0 uterus

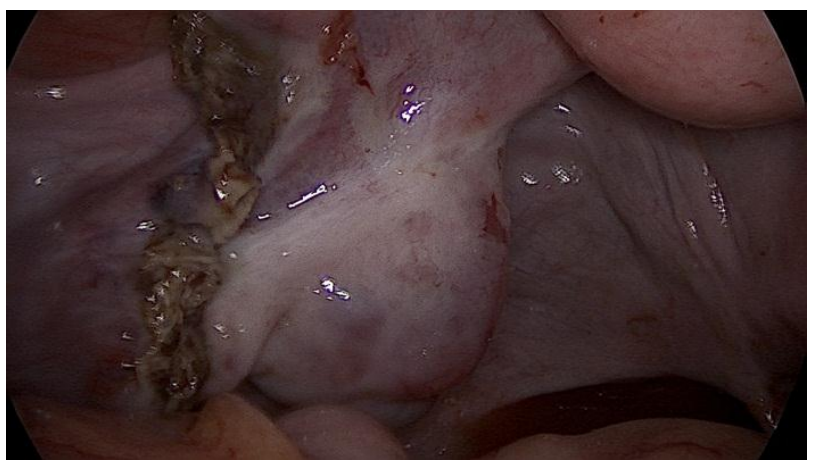

Fig. 8: Left side normal ovary with left salpingectomy hemaostais achieved

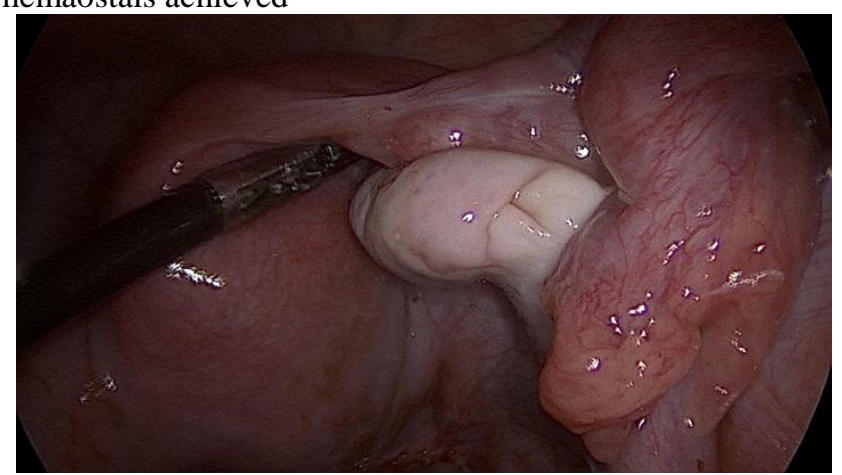

Fig. 9: right side normal tube and ovary

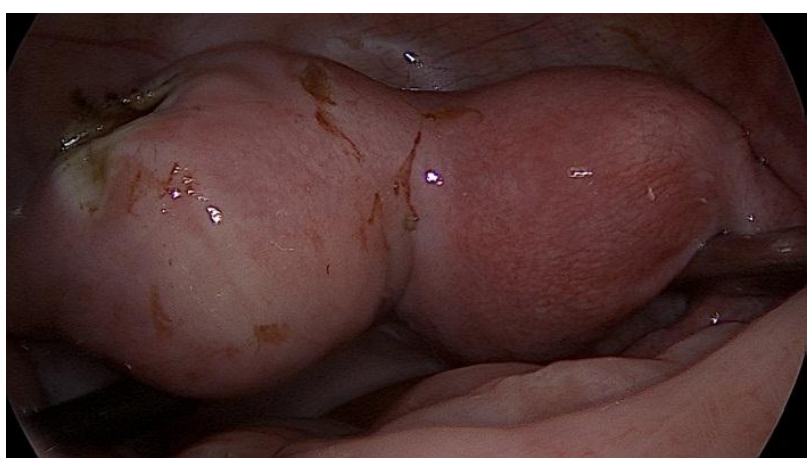

Fig 10: post operative view

There was a hemi uterus, with left non communicating horn with haematometra of about $6 * 8 \mathrm{~cm}$. It was drained by putting a $3 \mathrm{~cm}$ transverse incision on its ventral surface. Normal saline wash was given in the cavity of haematometra as is well said "All solution of pollution is dilution".

Haemostatis was achieved. No drain was kept patient had uneventful post op course $n$ was discharged the next day.

\section{Discussion}

Isolated Torsion of fallopian tube is a uncommon cause of lower abdominal pain. The incidence is estimated to be 1 in 5 lakh women ${ }^{7}$.

It is mostly found in women of reproductive age group but has also been reported in prepubertal and postmenopausal women. 
Causative mechanisms for fallopian tube torsion are not fully understood. Torsion can also affect previously healthy tubes.it is more commonly seen on right side ${ }^{.[8]}$

Hydrosalpinx: a blocked fluid filled tube is the most common lesion associated with fallopian tube torsion.it may be unilateral or bilateral.

It can be due to PID-causing tubal occlusion, previous abdominal surgery, endometriosis, ectopic pregnancy and congenital malformation. ${ }^{1}$

Hydrosalpinx presentation is usually asymptomatic, but it may present with chronic pelvic pain, dyspareunia, or a sense of pelvic pressure.The diagnostic modalities include Ultrasound being the standard imaging modality. Hydrosalpinx appears as elongated, convoluted cystic mass, tapering as it nears uterine cornua, with ipsilateral ovary seen separate from the mass. Doppler of the affected tube helps to diagnose torsion. Absense of flow is indicative of torsion of hydrosalpinx. ${ }^{9}$

Management of isolated hydrosalpinx includes either detorsion or simple salpingectomy ${ }^{1 .}$ Laparoscopy serves not only as a diagnostic tool but also as an excellent therapeutic strategy with an added advantage of less pain less blood loss and smaller incisions in this era of day care surgeries. ${ }^{10}$

Timely diagnosis may allow conservative management of torsion in select cases with untwisting, draining the hydrosalpinx and conservative of tube. But in delayed cases this may not be possible due to irreversible damage to the tissue.

In this case, hydrosalpinx was complicated by presence of unicornuate uterus with non-communicating rudimentary horn. Due to non-communication, if endometrium becomes active, it leads to haematometra ${ }^{8}$. In such cases patient may complaint of cyclical lower abdominal pain and dysmennorhoea. ${ }^{11}$

\section{Conclusion}

A 18 years old unmarried female came to OPD for mild lower abdomen pain. As per USG finding she diagnosed as twisted hydrosalpinx with hemi uterus with non communicating horn with haematometra. Laparascopic salpingectomy with drainage of haematometra was done.
Future surgery - Patient was counseled about the non functioning status of left sided horn of uterus and need for future removal of this horn. ${ }^{12}$

\section{Conflict of Interest: None.}

\section{Reference}

1. https://en.wikipedia.org/wiki/Hydrosalpinx

2. Shukla R. Isolated torsion of the hydrosalpinx: a rare presentation. Br J Radiol 2004;77(921):784e-86

3. Atri M., de Stempel J., Bret P.M. Accuracy of transvaginal ultrasonography for detection of haematosalpinx in ectopic pregnancy. J Clin Ultrasound 1992;20:255-61.

4. Borgohain D. Pregnancy in bicornuate uterus; Int J Reprod Contracept Obstet Gynecol 2018;7(1):346-8.

5. The ESHRE/ESGE consensus on the classification of female genital tract congenital anomalies. Human Reprod 2013;28(8);2032-44, Advanced Access publication on June 14, 2013 doi:10.1093/humrep/det098

6. Ghossain M.A., Buy J.N., Bazot M. CT in adnexal torsion with emphasis on tubal findings: correlation with US. J Comput Assist Tomogr 1994;18(4):619-25.

7. Hansen O.H. Isolated torsion of the fallopian tube. Acta Obstet Gynecol Scand 1970; 49(1):3-6.

8. Madhusudan Dey, Lt Cola,* and Reema Kumar, Lt Colb.Isolated torsion of hydrosalpinx. Med J Armed Forces India 2013;69(2):178-80. Published online 2012 Sep 14. doi: 10.1016/j.mjafi.2012.04.016

9. M. A. Aboulghar, R. T. Mansour, and G. I. Serour, "Controversies in the modern management of hydrosalpinx," Human Reprod Update 1998;4(6);882-90.

10. Rock JA. Surgery for anomalies of the mullerian ducts. In: Rock JA, Thompson JD (eds). Telinde's operative gynecology. Philadelphia; Lippincott-Raven, 1997:710-21

11. Fedele L, Marchini M, Baglioni A, Carinelli S, Zamberletti D, Candiani GB. Endometrium of cavitary rudimentary horns in unicornuate uteri. Obstet Gynecol 1990;75:437-40.

12. Heinonen PK. Clinical implications of the unicornuate uterus with rudimentary horn. Int J Gynecol Obstet 1983;21:145-50.

How to cite this article: Pandya M, Tekani $\mathrm{D}$, Shah $\mathrm{S}$. A rare case of twisted hydrosalpinx with CONTUA: ESHERE: ESGE: Class IV a COV0 uterine anomaly. Indian J Obstet Gynecol Res 2019;6(2):239-242. 